\title{
Aportaciones a la historia del género ambiguo en español: a propósito del sustantivo deverbal tizne
}

\section{Contributions to the History of the Ambiguous Gender in Spanish: the Case of the Deverbal Noun tizne}

\author{
Pilar Montero Curiel \\ Universidad de Extremadura \\ pmontero@unex.es
}

\section{Resumen}

La Nueva gramática de la lengua española (2009) define los sustantivos ambiguos en cuanto al género como aquellos que se refieren a una misma entidad, inanimada, tanto en masculino como en femenino, pero «no designan, por lo general, seres sexuados». Algunos pueden analizarse como desarrollos tardíos, posteriores a la reestructuración de géneros que siguió a la pérdida del neutro y de la flexión casual, unidos a bases verbales que muestran vacilaciones semejantes a las originadas tras los procesos evolutivos surgidos en el paso desde el latín a las lenguas romances. Entre ellos, tizne, cuyas variaciones a lo largo de la historia del español serán el objeto fundamental del presente estudio.

Palabras Clave: género ambiguo, sustantivos deverbales, tizne, español

\section{Abstract}

The New Grammar of the Spanish Language (2009) defines ambiguous nouns in terms of gender as those that refer to the same inanimate entity, both male and female, «but do not usually designate sexed beings». Some can be analyzed as late developments, after the restructuring of gender that followed the loss of neutral and casual flexion, together with verbs roots that show similar vacillations to those originated after the evolutionary processes that emerged in the transition from Latin into Romance languages. Among them we find the case of the word tizne, whose variations throughout the history of the Spanish language will be the fundamental object of the present study. ${ }^{1}$

\footnotetext{
${ }^{1}$ Mi gratitud a David Sotoca por la revisión de este resumen y sus atinadas correcciones.
} 
KEYWORDS: ambiguous gender, deverbal nouns, tizne, Spanish

FECHA DE RECEPCIÓN: 21/05/2020

FECHA DE ACEPTACIÓN: 07/10/2020

\section{Introducción}

Algunos sustantivos son ambiguos en cuanto al género porque se emplean indistintamente con determinantes masculinos o femeninos sin modificar sus significados (NGLE, 2009, p. 83; Alcina y Blecua, $1983^{4}$, pp. 543-525; Alarcos, 1994, p. 62; Ambadiang, 1999 , p. 4857). La mayoría de ellos no designa seres sexuados y su empleo depende, en muchos casos, de fenómenos de variación diatópica y, en menor medida, diastrática, según el nivel sociocultural de los hablantes. Otros reflejan vacilaciones diacrónicas muy antiguas, originadas por la acomodación de los géneros latinos al sistema romance o por su desarrollo tardío en la lengua como derivados de otras categorías. Es lo que sucede en español con algunos sustantivos como tizne, considerado hoy ambiguo en cuanto al género por la Real Academia Española y las Academias correspondientes en el diccionario usual (DLE 2014: s.v. tizne) y en la Nueva gramática de la lengua española (2009, pp. 113-119). Como ocurre con otros sustantivos de génesis similar, hace referencia a un ente no sexuado y, según apunta el diccionario académico, tiene un origen verbal claro. Cumple, además, con el precepto de no ser utilizado indistintamente por los mismos hablantes "con los dos géneros, en las mismas expresiones y sin diferencias de significado" (NGLE, 2009, p. 113), como se deduce de la extensa documentación escrita en castellano, suministrada hoy por los diccionarios de la lengua española, por las bases de datos léxicas de enfoque diacrónico y sincrónico, y por el Fichero general de la lengua española de la Real Academia, fuentes que ayudarán a interpretar el alcance de sus vacilaciones en todo el dominio lingüístico hispanohablante.

En relación con el origen de tizne, hay que apuntar que en español el sufijo - e es un derivado vocálico átono muy rentable (junto con $-a \mathrm{y}-o$ ) en la formación de sustantivos deverbales 
(Pena, 1980 y 2018). Según la gramática académica, estos sustantivos no eran frecuentes en latín, "pero crecieron rápidamente en español" (NGLE, 2009, p. 370) y su presencia fue aumentando con el tiempo, aunque de forma desigual: los terminados en las vocales - a y -o (ayuda, caza, cambio, ruego) irrumpieron con mayor fuerza en los textos primitivos que los que lo hacían en -e (alcance). Todos ellos, pero de manera especial los terminados en - $e$ y en $-o$, fueron "ganando terreno desde el siglo $\mathrm{xv}$ " en un proceso de expansión que ha llegado hasta nuestros días con un gran rendimiento funcional, sobre todo en el español americano (NGLE, 2009, pp. 370-371; Pena, 1980, 2012 y 2018).

Desde un punto de vista morfológico, estos sufijos "anulan la vocal temática del verbo al que se adjuntan”, según explica la gramática académica con ejemplos del tipo engañar > engaño, además de desplazar el acento agudo del infinitivo para eliminarlo de la misma vocal temática: desear (aguda) > deseo (llana), anomalía que algunos autores, según aclara la propia Academia, justifican al observar que los sufijos vocálicos se forman sobre los temas de presente (pues respetan las pautas vocálicas de estos) y no a partir de los infinitivos (NGLE, 2009, pp. 371-372). Ambas premisas se cumplen en el vocablo que nos ocupa.

Además, entre las conjugaciones verbales del español parece ser la primera, la de los verbos terminados en -ar, la más productiva en este tipo de formaciones: de ella resultan nombres terminados en -a (ayuda, baja, busca, compra, compulsa, estafa, firma, friega, muda, veda, zurra), en -o (abandono, abasto, abrazo, asombro, bautizo, canto, castigo, degüello, descargo, empeño, encanto, gobierno, grito, manejo, pago, rasguño, saldo, saludo, uso, vuelco) y en -e (afeite, arranque, baile, cierre, choque, derrumbe, desfile, empuje, encaje, frote, pliegue, realce, rescate, tizne). Como se puede observar, los derivados en - $a$ son femeninos; los que terminan en $-e$ y en $-o$, masculinos, y solo algunos de los terminados en - $e$ pueden ser ambiguos en cuanto al género, como sucede con tizne.

Para clasificarlos, la Academia (NGLE, 2009, pp. 375-378) ofrece una división basada en el significado: muchos de estos sustantivos denotan acción (ayuda, carga, demora, reforma, refriega, afeite, roce, saque, vislumbre, abandono, alboroto, desembolso, desenfado, traspaso; véase Díaz Hormigo, 2011). Otros admiten 
la interpretación de efecto (pesca, reforma, corte, rebaje, rebote, abono, acuerdo, adobo). Algunos hacen referencia a cantidades económicas (importe, ajuste, desgrave, ingreso, adelanto, adeudo, ahorro, debido, desembolso). Hay otros que se asocian a sonidos de distinta naturaleza (grito, hipo, lloro, lamento, relincho, silbo) y otros muchos que designan instrumentos, medios o recursos (acople, cierre, enchufe, enganche y remolque).

Uno de los problemas que plantean estos vocablos es el que la propia Academia denomina "dirección del proceso derivativo", que consiste en averiguar si "se produce la derivación de verbos a partir de sustantivos o la de sustantivos a partir de verbos" (NGLE, 2009, p. 380). Para aclarar este escollo toma en cuenta tres criterios:

a) Atender a las fechas de documentación del verbo y su derivado (criterio histórico).

b) Considerar la existencia de pautas en la morfología sincrónica que permitan decidir entre las dos posibilidades (criterio formal).

c) Analizar los elementos que aparecen en las definiciones de los vocablos para poder dilucidar las direcciones de los procesos (criterio lexicográfico).

En el caso del sustantivo tizne y del verbo tiznar las primeras documentaciones que proporciona la base de datos CORDE ${ }^{2}$ coinciden en la fecha de 1527 para ambos vocablos en la Apologética historia sumaria de Fray Bartolomé de las Casas, aunque el fichero general de la Real Academia Española (dentro de la web del Nuevo diccionario histórico del español) ${ }^{3}$ lleva al año 1465 el primer registro de tizne en castellano, incluido en una composición del poeta cancioneril madrileño Juan Álvarez Gato.

Corominas y Pascual (DCECH, s.v. tizón) entienden el verbo tiznar como un derivado de tizón que se formó a partir del verbo frecuentativo tizonear, continuador de un hipotético ${ }^{\star}$ tizonar que ellos deducen de la forma tizonador 'atizador', presente en

\footnotetext{
${ }^{2}$ https://www.rae.es/recursos/banco-de-datos/corde (diciembre-enero de 2020). ${ }^{3}$ http://web.frl.es/fichero.html (recuperado el 8 de enero de 2020). El ejemplo procede de la página 115 de la edición de Artiles.
} 
versos del Arcipreste de Hita al lado de tizonar. Entienden que este verbo pudo pasar fonéticamente a tiznar (con pérdida de la vocal pretónica), variante que se encuentra también en el mismo Juan Ruiz y, más tarde, en el vocabulario de Alonso de Palencia y en el de Nebrija. Todas son documentaciones tempranas que, de acuerdo con las leyes de la síncopa, fijan esa forma bisílaba en el infinitivo que ha llegado al español actual sin grandes cambios. El mismo Fichero general de la RAE, mencionado más arriba, proporciona ejemplos del verbo sincopado desde los tiempos de Juan Ruiz, que emplea el participio en los versos "diom' pan de çenteno I tyznado, moreno", hasta nuestros días en todo tipo de autores y regiones del español. Los corpus consultados, y la inexistencia de documentación para apoyar una posible variante ${ }^{\star}$ tízone (forma plena, de acentuación esdrújula, a partir de tizonear), confirmarían también esta génesis derivativa de dos vocablos unidos, además, por un mismo parentesco semántico.

Estamos, por tanto, ante un sustantivo cuyo origen parece claramente verbal con vacilaciones de género que han perdurado hasta nuestros días (Rosenblat, 1947), tal y como recogen la última edición del Diccionario de la lengua española (DEL, 2014: s.v. tizne $)^{4}$ y las bases de datos léxicas del ámbito hispano. Estas alternancias de género serán fundamentales para arrojar nuevas luces sobre un capítulo importante de la gramática histórica hispana: el del género de algunos sustantivos y sus variaciones en la evolución de la lengua a un lado y otro del Atlántico (Montero, 2019). A analizar la historia de tizne, y las vacilaciones asociadas al carácter ambiguo de su género, vamos a dedicar las páginas que siguen.

\section{El sustantivo tizne en los diccionarios de la lengua española}

La temprana presencia de tizne en castellano se ve respaldada por los repertorios de vocabulario ${ }^{5}$ desde los tiempos de Nebrija

\footnotetext{
${ }^{4}$ https://dle.rae.es/tizne?m=form (5 de febrero de 2020).

5 Todas las referencias a los diccionarios antiguos del español, desde Nebrija hasta la edición de 1992, provienen del Nuevo tesoro lexicográfico de la lengua española (NTLE), s.v. tizne, recuperado de la web de la Real Academia Española http://ntlle.rae.
} 
(que lo identifica en 1495 con el sentido de "hollin" equivalente al vocablo latino FULIGO, -INIS, al lado del verbo tiznar y el participio tiznado) hasta nuestros días. Su definición proporciona pistas a la mayoría de los diccionarios bilingües de los siglos XVI y XVII (Fray Pedro de Alcalá, 1505; Cristóbal de las Casas, 1570; Richard Percival, 1591; Juan Palet, 1604; César Oudin, 1607; Girolamo Vittori, 1609; Lorenzo Franciosini, 1620 y Baltasar Henríquez, 1679) que registran el verbo tiznar y el sustantivo tizne sin identificar en ningún caso el género de este último.

Sebastián de Covarrubias (1611), en la tradición de Nebrija, lo entiende como continuador, desde el punto de vista semántico, del vocablo latino fuligo, 'hollín de la chimenea'. En la entrada correspondiente al verbo tiznarse se descubre que, para el lexicógrafo toledano, el sustantivo tizne es masculino: "enjorginarse y denegrarse con el tizne”. En la misma línea, Francisco Sobrino, en su Diccionario nuevo de las lenguas española y francesa (1705), indica un siglo después que tizne es un sustantivo masculino equivalente al francés "le noire des poiles". Su testimonio resulta muy interesante porque refuerza, junto con el de Covarrubias, las hipótesis de Corominas y Pascual (inspiradas también por el Tesoro) sobre el primitivo origen masculino del vocablo.

El Diccionario de Autoridades (1739) ofrece las primeras conjeturas sobre tizne como un sustantivo de género ambiguo, sinónimo de hollín, con el sentido de "humo, que se pega à las sartenes, peroles, y otros vasos, que han estado à la lumbre"; los ejemplos literarios con los que ilustra su definición apoyan este carácter ambiguo en dos autores coetáneos: Quevedo (1580-1645), en femenino, escribe que "ya no se sabía qual era el carbonero, ni quien había pegado la tizne al otro", mientras que el poeta murciano Jacinto Polo de Medina (1603-1676) prefiere el masculino en los versos "usurpando el candór al mejor Cisne / Por cubrir de mi Musa el negro tizne".

Como se puede observar, el primer repertorio académico sienta las bases de la definición que se da del vocablo tizne en todas sus versiones dieciochescas $(1780,1783,1791)$, como sus-

es/ntlle/SrvltGUIMenuNtlle?cmd=Lema\&sec=1.1.0.0.0 el 5 de noviembre de 2019 y entre los días 1-16 de enero de 2020. 
tantivo ambiguo en cuanto al género, sinónimo de hollín, con el sentido ya apuntado de "humo que se pega à las sartenes, peroles y otros vasos, que han estado à la lumbre". En el último cuarto del siglo XviII, Esteban de Terreros y Pando usa tizne en masculino. Sin determinar la categoría gramatical del vocablo, lo define como sinónimo de hollín y como "materia que se pega à sartenes, y por analogía se dice tizne o tiznón de la mancha, o deshonor", acepción metafórica que ilustra con un ejemplo en el que queda claro el uso masculino apuntado: "No se le quitará tan presto el tizne que con una acción tan fea se le ha pegado".

En 1825, Manuel Núñez de Taboada, en la tradición académica (que él mismo asume en las preliminares y en el enfoque de su Diccionario de la lengua castellana), define tizne como sustantivo de género ambiguo. Le siguen Vicente Salvá (1846), Elías Zerolo (1895), Miguel de Toro y Gómez (1901), José de Alemany y Bolufer (1917) y las ediciones del repertorio académico publicadas entre 1832 y 1914. El Diccionario usual de 1925 (y también el Manual de 1927) agregan información gramatical complementaria al señalar que, aunque ambiguo, el sustantivo tizne se usa más como masculino en castellano, y añaden un segundo sentido sinonímico (solo para el uso masculino) que remite a la primera acepción de tizón, 'palo a medio quemar. Estas observaciones rigen los usos atribuidos al sustantivo que nos ocupa hasta el día de hoy: la norma académica mantiene la definición de 1925 (en las versiones publicadas entre 1936 y 2001) y la mayoría de los lexicógrafos posteriores se adhieren a ella.

Fuera de la tradición académica, María Moliner (1968, s.v. tizne) explica que tizne es "masculino y — no usual- femenino". Manuel Seco (1999, s.v. tizne) lo define como "masculino (o femenino)" y explica las cuatro acepciones que ofrece el vocablo en el español actual: 'hollín', 'tizón', 'tiznón' y 'negrilla del olivo', especie de parásito conocido también como mangla, en un uso recogido a mediados del siglo xix por Miguel Colmeiro en su Diccionario de los diversos nombres vulgares de muchas plantas usuales ó notables del Antiguo y Nuevo Mundo, según el Fichero General de la Lengua Española (RAE). Todos estos testimonios confirman, con sus matices restrictivos en algunos casos, la ambigüedad inherente al género del sustantivo que nos ocupa. 


\section{El género ambiguo del sustantivo tizne}

El Diccionario de la lengua española, en su vigesimotercera edición (2014), toma el sustantivo tizne como un derivado del verbo tiznar con dos acepciones: la primera corresponde a un sustantivo de género ambiguo (m. o f.) con el sentido de "humo que se pega a las sartenes, peroles y otras vasijas que han estado a la lumbre"; la segunda muestra un uso exclusivamente masculino del vocablo con el significado de "tizón o palo a medio quemar". 6

\subsection{Usos femeninos de tizne}

Según Corominas y Pascual (DCECH, s.v. tizón), en los orígenes de su empleo el vocablo "hubo de ser masculino", y así lo registran en Jacinto Polo de Medina (1603-1676) y en uno de los ejemplos con los que el Diccionario de Autoridades (1739) ilustra su definición. En algún momento de la historia del castellano pudo cambiar de género por analogía con otros femeninos terminados en -e, como mugre, pringue, podre (muy próximos a tizne desde el punto de vista semántico) entre los cuales solo pringue muestra hoy signos de ambigüedad en la vigesimotercera edición del Diccionario de la lengua española; mugre 'suciedad grasienta' y podre 'putrefacción' se definen ya como sustantivos femeninos.

El Fichero general de la Real Academia Española ofrece un ejemplo primitivo del uso femenino de tizne en un poema del madrileño Juan Álvarez Gato, compuesto entre 1465 y 1495, que adelantaría en algo menos de un siglo los primeros registros de uso del sustantivo en español aducidos por los repertorios etimológicos al uso: "Pues virtud os torna neto, / en perfeçion de bondad / y saber claro discreto, / prudencia, mucho perfeto, / desta tizne os alynpiad", testimonio interesante, porque invita a reflexionar sobre el original predominio del masculino tizne apuntado por Corominas.

Por las bases de datos léxicas de la Real Academia Española se adivina que el femenino tizne es habitual en textos del siglo

\footnotetext{
${ }^{6}$ Real Academia Española, Diccionario de la lengua española, <http://www.rae.es $>$ el 9 de febrero de 2020, s.v. tizne.
} 
XVI, en convivencia con el masculino: se encuentra en la Apologética historia sumaria de Fray Bartolomé de las Casas (15271550), en diversas escenas en las que el autor describe las costumbres indígenas y apunta que, en rituales funerarios, "lávanse y límpianse de la tizne que por luto se deben haber puesto"; en festividades religiosas, para honrar a sus dioses, "la media noche todos se bañaban y lavaban y con la tizne se tiznaban y ennegreábanse". También emplea el vocablo cuando explica que los indios fabrican un producto parecido al pan: tras conseguir una masa vegetal la dejan reposar al sol entre uno y tres días, al cabo de los cuales aparece llena de gusanos "tan negros poco menos que una tizne". En la Historia de las Indias transfiere el género inherente al sustantivo tizne, sin determinante, a un adjetivo calificativo: "úntanse con tinta o tizne negra". Como se ve, este sustantivo es frecuente en escritos del dominico sevillano, siempre en contextos en los que se habla de fuego y humo, con y sin determinante, o en enunciados en los que un objeto se compara con otro de color oscuro. El mismo género femenino aparece en un documento anónimo, procedente del México colonial (1541), que, al narrar los sacrificios ofrecidos a los dioses, apunta que la tizne era utilizada para teñir los rostros: “¿Cómo me tengo de poner este color negro, que es de mi dios Caricaueri? ¿Qué es esta tizne?”.

En 1569, Fray Luis de Granada, en su Manual de diversas oraciones y espirituales ejercicios, emplea el femenino cuando habla de la salvación del alma y escribe que "hallándose en ella la tizne de los pecados y el hedor de la mala vida, es luego atormentada con terrible espanto".

Como indicaba el Diccionario de Autoridades, también Quevedo se inclina por el uso femenino del vocablo; al ejemplo apuntado por los primeros académicos hay que añadir otros similares procedentes de textos poéticos, todos allegados por el CORDE, en algunos de los cuales descubrimos que las cejas y el cabello canosos se disimulaban con tizne, técnica que figura en otros muchos textos y autores del Siglo de Oro: "la tizne, presumida de ser

\footnotetext{
${ }^{7}$ Por ejemplo, Góngora, en algunos de sus romances, menciona la costumbre de usar este afeite como tinte: "con muy grandes cejas, / y es tizne, o carbón”; “y, aunque más encubras / con tizne las cejas, / ya de muy traýdas / se te caen y pelan”.
} 
ceja", "mi nevada pluma en sucia tizne", "la tizne decía: / seré cejas toda”, escribe Quevedo en poemas satíricos muy conocidos. También en su prosa asoma el femenino: "el miserable, que del miedo del tufo y de la tizne, no se osaba meter en medio", "ni quién había pegado la tizne al otro", "y el tris de la tizne" son ejemplos que aparecen en 1635 en La hora de todos y la Fortuna con seso, sátira política de valor excepcional también desde el punto de vista lingüístico. En fechas cercanas, Bernardo de Balbuena habla de un embustero que quiere "en negra tizne y vano pasatiempo / las canas esconder".

En la misma línea se sitúan los escritos de Fray Juan Bautista de la Concepción, que, en sus Diálogos entre Dios y un alma fingida (hacia 1613), se inclina por el femenino: "no tenía que tener miedo ni peligro de que se le pegaríe la tizne y suciedad de estas cosas bajas"; Lope de Vega, en la comedia titulada Servir a señor discreto (1618), invoca a una dama mulata como “ $\mathrm{iAh}$, tizne mía!"; Rodrigo Carvajal y Robles, en su Poema del asalto y conquista de Antequera (1627), habla metafóricamente de "la tizne de la noche escura" y de "la tizne de sus sombras", también en referencia al anochecer. Juan de Zabaleta alude a la "tizne trasnochada" (1654) como los restos de afeites y cosméticos que permanecen en la cara tras un largo día de fiesta. Estas referencias pueden completarse con las aducidas por el Fichero general de la RAE, que menciona al "príncipe de la tizne" en la Casa del plazer honesto (1620) de Salas Barbadillo. "La tizne del humo de copal" aparece en uno de los capítulos de la Historia general de la República del Ecuador, escrita en 1882 por Federico García Suárez, y "la tizne pegajosa de las teas", en un texto de Ángel Ganivet (1897) sobre la conquista del reino maya.

La base de datos CORDE no proporciona más ejemplos del femenino hasta el último cuarto del siglo xix. En uno de los Episodios Nacionales de Benito Pérez Galdós, La batalla de los Arapiles (1875), se dice que "creen que nos estorba la tizne". También aparece el femenino en El Bandolerismo, de Julián Zugasti, escrito entre 1876 y 1880: "que pretenden cubrir la tizne de su historia bajo los dorados escudos de títulos mendigados". Juan Valera, en su discurso académico sobre el misticismo en la poesía española, habla de "gentes alalas, antropiscas y negras como la tizne". 
El 1916, Juan Ramón Jiménez describe a la hija del carbonero de su Platero y yo como "bonita y sucia cual una moneda, bruñidos los ojos y reventando sangre los labios entre la tizne", y años después Rafael Alberti habla de un barrio humilde donde la gente "se da cabezazos contra la tizne de las paredes". Finalmente, en una traducción al castellano del Enchiridion fechada en 1932 asoma también el femenino: "no hay ninguna doctrina que sea puramente humana que no tenga por algún cabo alguna tizne de error", según el Fichero general de la RAE.

\subsection{Usos masculinos de tizne}

Coincidiendo con las primeras documentaciones literarias femeninas de tizne, Álvar Núñez Cabeza de Vaca (1527-1555), en sus Naufragios (1542), prefiere la versión masculina del sustantivo para describir una tradición funeraria indígena semejante a la narrada por Bartolomé de las Casas: "házenle las honrras del muerto y láuanse y límpianse del tizne que traen”, incluido el determinante en una contracción con la preposición de que no alberga ninguna duda sobre la identidad masculina del nombre al que presenta.

También el misionero franciscano Toribio de Benavente prefiere el masculino en un capítulo de su Historia de los indios de la Nueva España (1536-1541) cuando explica que los indios utilizaban tizne para pintarse de color oscuro los rostros, "y luego con aquel tizne se tornaban a entiznar y parar negros". El anónimo autor del Lazarillo de Tormes, según el fichero de la RAE, habla de "el tizne de las sartenes".

A finales del siglo XVI, José de Acosta usa el masculino en su Historia natural y moral de las Indias (1590) cuando refiere que una de las clases de guerreros indígenas del antiguo México estaba representada por el "señor de la casa negra o de negrura, por un cierto tizne con que se untaban los sacerdotes". Costumbre similar a la narrada por Fray Gerónimo de Mendieta en 1604, también con el sustantivo en masculino ("luego con el tizne que les habían dado se paraban negros"). Por las mismas fechas, Fray Prudencio de Sandoval refiere en una biografía de 
Carlos V que un esclavo negro, que asistía al emperador en su cámara, le cedía a menudo sus ropajes, y tiznada la cara, le ayudaba a salir del alcázar al anochecer sin que "nadie pudiese echar de ver el tizne fingido". También Baltasar Gracián elige el masculino de tizne en El Criticón (1653) y el Padre Isla (1787), en su Descripción de la máscara o mojiganga, habla de "tizne más generoso". Torres Villarroel prefiere el masculino: "no cambio por mis tiznes públicos las exteriores blancuras de los otros", escribe en los Sueños morales. ${ }^{8}$ Más tarde, Eulogio Horcajo (1883) habla "del tizne de la culpa", igual que Galdós en Fortunata y Jacinta (1885-1887) y en otros relatos posteriores. La misma opción eligen Emilia Pardo Bazán, en un relato de 1903, y Juan Eugenio de Hartzenbusch, que en una de sus fábulas habla de "el más pequeño tizne que manche un rostro". Antonio Machado se inclina por el masculino en unos versos de sus Soledades, galerías y otros poemas (1898-1907) cuando pregunta “¿No borrarán el tizne de tu cara / lágrimas verdaderas?".

En Hispanoamérica, el novelista colombiano Tomás Carrasquilla, en Frutos de mi tierra (1896), escribe sobre "la funda del tizne". El argentino Leopoldo Lugones, en su Lunario sentimental (1909), habla del "vago tizne". El guatemalteco Miguel Ángel Asturias (1926) narra que "la noche se inicia con el tizne que deja en las manos de los que leen el periódico la tinta fresca" y, en su novela El Papa Verde, relata que un capitán ordenó a un soldado "que se lavara el tizne de la cara". La cubana Dulce María Loynaz, en su novela lírica titulada Jardín (1935), habla de un pabellón abandonado después de un incendio que lo deja todo "impregnado del mismo tizne y la misma sombra ahumada". El poeta puertorriqueño Luis Palés Matos (1937) solo usa el masculino: "de todo tizne terreno" y "la sombra amplía su informe tizne sobre la ciudad", enunciado aparentemente ambiguo en el que informe funciona como adjetivo y tizne, como sustantivo.

De la relación anterior se infiere que entre los 122 ejemplos del uso de tizne que proporciona el CORDE, distribuidos en 97

\footnotetext{
${ }^{8}$ Ejemplos del Fichero General de la RAE, recuperados el 8 de enero de 2020, s.v. tizne, que completan la información proporcionada por las bases de datos léxicas.
} 
documentos, 109 son sustantivos; de ellos, 20 son masculinos y 21, femeninos; los 68 restantes no se relacionan en sus enunciados con categorías (determinantes, adjetivos) capaces de informar sobre el género de tizne y por eso no se los ha tenido en cuenta. Las 13 formas verbales del presente de subjuntivo que completan el registro de formas quedan, lógicamente, fuera de las intenciones de este trabajo.

Desde el punto de vista cronológico, el femenino domina en textos de los siglos XVI y XVII, y empieza a ceder terreno al masculino a partir del xviII, de forma que en la literatura actual española e hispanoamericana sobresale el masculino, coherente con la observación que ofrece el Diccionario de la lengua española sobre el predominio de este género en los usos del sustantivo que nos ocupa, y con las observaciones de algunos lexicógrafos de mediados del siglo xx, como el colombiano Roberto Restrepo que, en sus Apuntaciones idiomáticas y correcciones del lenguaje, escribe en 1945: "Podremos decir el tizne o la tizne (más usada la primera) cuando se habla del humo que se pega a las sartenes, etc. Pero cuando con este nombre se designa al tizón ha de ser siempre masculino". También el venezolano Francisco de Sales Pérez habla de "un carbonero vestido de casaca que siempre tiene un tizne en las orejas" (1871 y 1877). Faustino Sarmiento, argentino, en sus Recuerdos de provincia (1880), prefiere el masculino ("el tizne", "el sucio tizne").

Las cifras anteriores se ven respaldadas por la base de datos CREA, que suministra 45 casos de tizne en 37 documentos procedentes de España y América datados entre 1976 y 2004. ${ }^{9}$ Entre

\footnotetext{
${ }^{9}$ De los argentinos Ana Zaefferer, Jorge Bucay y Tomás Eloy Martínez; el chileno José Donoso; el cubano Miguel Barnet; el guatemalteco Rodrigo Rey; los mexicanos Guillermo Chao, Jorge Volpi, Guillermo Schmidhuber, Marcos López, Electra Mompradé, Sergio Pitol, David Martín del Campo, Aura Vega, Janny Hayen, Eladia González, Tomás Mojarro y Carmen Aguilera; el peruano Jorge Lira; la puertorriqueña Mayra Santos; los uruguayos Eduardo Galeano y Armonía Somers; los venezolano Arturo Uslar Pietri y Benigno Dou, así como los españoles Antonio Ruiz, Eduardo Chamorro, Camilo José Cela, Juan Marsé, Rosa Montero, Arturo Pérez-Reverte. Real Academia Española: Banco de datos (CREA) [en línea]. Corpus de referencia del español actual. <http://www.rae.es> [6 de enero de 2020]. No se encuentran testimonios de esta alternancia en Quesada Pacheco, 2013.
} 
ellos, 25 son masculinos y los otros 20 no ofrecen información sobre el género al emplearse el sustantivo sin el apoyo de otras categorías gramaticales. No muestra este corpus ningún ejemplo de uso del femenino; sí los ofrece, aunque de forma esporádica, el banco de datos del español del siglo xxi, el CORPEs, en 66 referencias procedentes de 58 documentos posteriores todos al año $2000 .{ }^{10}$ Entre ellos, solo 3 usan el sustantivo tizne en femenino, dos veces en textos firmados por el profesor y académico Francisco Rico, que escribe en 2003 y 2011: "una palabra ajena a la intención del autor, una frase que cojea manifiestamente, un agravio al sentido común, ¿son menos importantes que una nota desafinada o la tizne que esconde un matiz?". El tercer ejemplo pertenece al relato del madrileño Armando López Salinas titulado "La huelga": "ya estará la mujer sacando la tizne del puchero, esperando la vuelta para llenarlo". Los tres ejemplos se encuentran en textos firmados por autores españoles; los restantes usos del masculino (30 en total) se documentan en escritos de todo el dominio lingüístico del español, tanto europeos como hispanoamericanos. Esto significa que solo el $9 \%$ de los textos contemporáneos prefiere el femenino; el 91\% restante opta por el masculino, en consonancia con los dictados de la norma académica. A este conjunto hay que añadir los 33 casos que no ofrecen apoyos en otras palabras para determinar sus preferencias de género, pero que pueden interpretarse como masculinos, porque muchos aparecen en los mismos textos de escritores que han manifestado sus inclinaciones a favor de este género en textos similares.

Entre los atlas lingüísticos del mundo hispano, el ALEANR (Aragón, Navarra y Rioja) registra el femenino en un municipio de Burgos (en los límites con la zona estudiada por el atlas) y en cuatro localidades turolenses. El resto del dominio encuestado (todas las provincias de Logroño y Zaragoza, y buena parte de Navarra y Teruel) muestran el predominio del género masculino en el mapa relativo a este concepto. Apoya esta situación el

\footnotetext{
${ }^{10}$ Real Academia Española: Banco de datos (CORPES XXI) [en línea]. Corpus del español del siglo XXI (CORPES). <http://www.rae.es> [6 de enero de 2020].
} 
ejemplo de tizne proporcionado por el Vocabulario riojano de Cesáreo Goicoechea (1961), con una acepción nueva de tizne, usual en la provincia de Logroño (por tanto, marcada diatópicamente), con el sentido de "vicio del trigo", paralela a la apuntada por Colmeiro y Seco sobre el parásito olivarero. El ALEA define el sustantivo tizne como ambiguo y muestra ejemplos de este carácter en el mapa 1741 en todas las provincias andaluzas, según los registros (para ambos atlas) del Fichero general de la Real Academia Española.

El género femenino, pese a la reducción de las referencias y a su carácter esporádico en la literatura, suele asomar en escritos de diversa índole en el español actual. En algunos casos ha pervivido en textos lexicalizados, como el topónimo urbano "Giro La Tizne" en la localidad cordobesa de El Carpio. ${ }^{11}$ En la misma provincia, un lector dirige una carta al Diario de Córdoba titulada "La tizne entre dos palacios", para denunciar los efectos de la contaminación sobre la fachada de dos edificios históricos. ${ }^{12}$ En Mairena de Alcor (Sevilla) un equipo de fútbol recibe el sugerente nombre de "Los ex de La Tizne" ${ }^{13}$ No falta el nombre "La Tizne" en una de las bodegas del itinerario de los vinos de Montilla (Córdoba). ${ }^{14}$ Por último, la calle "La Tizne" se localiza en Fuenlabrada de los Montes, en el extremo oriental de Badajoz.

Además, se encuentra el femenino lexicalizado en el contexto de algunos festejos tradicionales. En la localidad toledana de Escalona se celebraba el "Día de La Tizne", que ponía fin a las fiestas de San Vicente, y en el que "los mozos salían a tiznar a las mozas" ${ }^{15}$ En la localidad abulense de La Adrada se celebra el día de San Blas el "baile de La Tizne" "una antigua tradición que al principio se realizaba con patatas cortadas por la mitad

\footnotetext{
${ }^{11} \mathrm{https}: / /$ www.youtube.com/watch?v=8dDytamd0t0 (recuperado el 9 de enero de 2020). $12 \mathrm{https} / /$ www.diariocordoba.com/noticias/opinion/tizne-dos-palacios_933779.html (recuperado el 9 de enero de 2020).

${ }^{13} \mathrm{http} / /$ www.mairenadelalcor.org/export/sites/mairenadelalcor/.galleries/documentosnoticias/20716CRUCES.pdf (recuperado el 9 de enero de 2020).

${ }^{14} \mathrm{http}: / /$ cofradiavinomontilla.com/Cofradia/Tabernas/BiberonesBolero.htm (recuperado el 9 de enero de 2020).

${ }^{15} \mathrm{http}: / /$ www.caminandoporparedes.com/?p=3902 (recuperado el 9 de enero de 2020).
} 
y quemadas al fuego, con las cuales los lugareños se tiznaban la cara". ${ }^{16}$

Más próxima a los usos contemporáneos, la tienda Wiggle, que vende artículos deportivos por internet, ofrece en su página web unos artilugios que protegen las zapatillas de los ciclistas "frente a la tizne de la carretera". ${ }^{17}$

El ya mencionado parásito del olivo sigue apareciendo en femenino en abundantes páginas de agricultura (muchas de ellas originarias de la Andalucía olivarera) como "la cochinilla de la tizne", que en algunas ocasiones se identifica con los nombres populares de negrilla y fumagina, en referencia al parásito conocido técnicamente como Saissetia oleae.

El periodista Luis Miguel Fuentes, andaluz, escribe en El Mundo (12 de mayo de 2015) una columna titulada "La tizne y el vals". También en las páginas andaluzas del diario ABC asoma el femenino en una crónica cuyo autor ridiculiza el juego desafortunado del Sevilla contra el Granada y augura malos tiempos para su equipo, "salvo que la tizne que deshonra hoy el rostro de vuestro sevillismo de gominola se caiga en Lyon", escribe Félix Machuca el 7 de diciembre de 2016. ${ }^{18}$ Y en la pieza teatral del cordobés Miguel Romero Esteo, Pasodoble. El barco de papel (2008), el personaje llamado Monsieur Rafalot exclama: “¡Marinero de las tiznes, pídele todo el perdón a la sirenita de la mar!", un ejemplo del femenino plural, continuador de un uso localizado en 1604, en los Exercicios espirituales para todos los dias de la Quaresma, del madrileño Pedro de Valderrama, en un episodio en el que, al criticar las carnestolendas, el autor se pregunta por el escaso juicio que puede tener aquel que disfrute en la calle con "las calderas de agua, los naranjazos, las pelladas que se tiran, las tiznes". ${ }^{19}$

\footnotetext{
${ }^{16} \mathrm{http}: / /$ laadrada.net/la-adrada-celebra-el-baile-del-tizne-en-las-fiestas-de-san-blas/ (recuperado el 9 de enero de 2020).

$17 \mathrm{https} / /$ www.wiggle.es/cubrezapatillas-de-punto-giro/ (recuperado el 9 de enero de 2020).

${ }^{18} \mathrm{https} / / /$ sevilla.abc.es/deportes/orgullodenervion/opinion/la-opinion-de-felix-machuca/ pensad-granada-rabiad-115846-1481101626.html (recuperado el 9 de enero de 2020). ${ }^{19}$ https://books.google.es/(recuperado el 11 de enero de 2020).
} 
Y, fuera de las fronteras españolas, en México "La Tizne Tacomotora" es una cadena de restaurantes que se autodefine como "Unidad Generadora de Tacos al Humo Tizne". Es un ejemplo que hay que analizar aparte, porque aparece en un enunciado ambiguo desde el punto de vista de las categorías gramaticales que lo integran: si tizne se usa como sustantivo, tacomotora es un adjetivo que concuerda con él en género y número $;{ }^{20}$ pero también podría suceder que el sustantivo fuera tacomotora y tizne funcionara como adjetivo (situación que puede darse en el español coloquial mexicano, y de hecho se da en palabras como pinche, que tiene valor adjetivo, con el sentido de 'ruin', según el diccionario académico; o padre, que se usa como superlativo: "fue padre", 'estupendo').

De los ejemplos anteriores se infiere que en el español actual el uso del femenino se da preferentemente en España y, dentro de la península, son las provincias de la Andalucía occidental (sobre todo, Córdoba y Sevilla) las que ofrecen un mayor número de recurrencias. Esta observación podría significar que la ambigüedad del género de tizne queda ya sujeta a variación diatópica y es un rasgo bien localizado en la región suroccidental de la península ibérica, tanto en ejemplos lexicalizados como en los usos del habla viva que recoge la prensa regional.

\section{Reflexiones finales sobre el género de tizne en el español actual}

La presencia del sustantivo tizne en el español actual es cada vez más escasa, como evidencian las cifras anteriores. Su falta de funcionalidad en el vocabulario del siglo xxI podría atribuirse a la desaparición de su uso en la vida cotidiana, reflejo de modos de vida y costumbres obsoletos. Como muestran los ejemplos literarios allegados por las bases de datos y otras herramientas, tizne hace referencia a la mancha que deja el hollín o el humo de cualquier perol arrimado al fuego, y también al efecto de tiznar o

\footnotetext{
${ }^{20}$ https://twitter.com/TizneTacomotora (recuperado el 9 de enero de 2020).
} 
tiznarse la piel. Con este sentido, queda justificada su presencia en algunas crónicas de Indias que, como hemos podido constatar, refieren costumbres y rituales en los que se ennegrecían los cuerpos, siempre en relación con las prácticas ancestrales que dotaban al fuego y al humo de funciones purificadoras, o servían como remedios para ahuyentar los malos espíritus. En este contexto encaja muy bien el uso de tizne, con su ambigüedad de género, en los primeros textos del castellano que dan fe de su uso. Otra acepción muy reiterada en los documentos antiguos es la de medio para teñir el vello de las cejas, que asoma en la obra de Quevedo y es habitual en la literatura barroca. Ambos matices ponen de relieve que el tizne o la tizne se asocian con el color negro adquirido tras el contacto con el humo, el hollín o los tizones quemados, y justifican la presencia del mismo sustantivo en contextos en los que se pretende resaltar la suciedad de los rostros o de la materia en general (pensemos en los ejemplos de Juan Ramón Jiménez o Rafael Alberti, por citar dos autores relativamente cercanos a nuestros tiempos).

Con las referencias anteriores, y dada la parquedad de las cifras que suministran las bases de datos léxicas del español actual, podría afirmarse que el sustantivo tizne ha entrado en una fase de desgaste en el vocabulario activo de los hispanohablantes. La industria cosmética proporciona hoy herramientas mucho más eficaces para teñir la piel; también las modernas cocinas han contribuido a eliminar de las sartenes los residuos de tizne que resultaban del contacto con el fuego o el gas. Y estos hechos extralingüísticos, como sucede en otras parcelas del vocabulario vinculadas a costumbres tradicionales, pueden firmar en poco tiempo el acta de defunción de un vocablo que ha vivido durante siglos al abrigo de unos usos que hoy resultan extraños.

Desde el punto de vista lingüístico, se ha partido de la convicción (apuntada por la Real Academia Española y ratificada por Corominas y Pascual) de que tizne se formó a partir del verbo tiznar, resultado de la síncopa vocálica que sufrió la variante primitiva tizonear. Por esta génesis, se ha clasificado como un sustantivo deverbal cuyo proceso derivativo, tras la fijación del significante del verbo, conduce desde esta categoría hasta la del sustantivo, en este caso terminado en -e (en correspondencia formal con la primera 
y la tercera personas del singular del presente de subjuntivo, frente a las formas acabadas en - $a$ y en $-o$, que coinciden formalmente con la tercera persona del singular del presente de indicativo). A asumir esta dirección del proceso derivativo ayudan, además del parentesco léxico entre las dos formas (Mas Álvarez, 2004, p. 59), los datos suministrados por el CORDE, que ofrece ejemplos del participio del verbo tiznar en el Libro de buen amor de Juan Ruiz (1343): “diom' pan de çenteno / tyznado, moreno", como apuntaban Corominas y Pascual. Formas conjugadas del verbo aparecen en el Cancionero castellano del siglo XV de la Biblioteca Estense de Módena (1400-1500): "fuyamos lo que nos tizna / como la fragua al ferrero", fuente interesante porque recoge composiciones poéticas transmitidas oralmente, creadas mucho antes de su fijación escrita. Los dos registros apuntados atestiguan, ayudados por los abundantes datos que ofrece el Fichero general de la RAE desde finales del siglo Xv hasta hoy, la presencia del verbo en la lengua en textos de los siglos XIV y xv, y siguen las pautas marcadas por otras palabras en la morfología sincrónica castellana, como los muchos casos que recoge la NGLE (2009, p. 374), sobre todo en "la lengua juvenil, en la conversacional y en la deportiva": achique, alucine, cague, chute, deschongue, desmadre, desmelene, despijote, flipe, ligue, mate, pase, quite, rechace, refocile, regate, remate, saque, vacile son habituales en los registros citados. Todo ello sin dejar de lado algunas excepciones, como las representadas por linde y sangre, que muestran la dirección inversa del proceso derivativo, dado que en ambos casos los sustantivos dan origen a los verbos (lindar y sangrar, respectivamente) y no al revés (NGLE, 2009, p. 373).

Desde una perspectiva lexicográfica, las definiciones del vocablo tizne en los diccionarios de la lengua española ponen de manifiesto su relación con el verbo tiznar, aunque hay que tener en cuenta que las dos categorías gramaticales muestran en castellano una historia paralela, porque cuando aparecen en este tipo de textos lo hacen a la vez y es Antonio de Nebrija el responsable de las documentaciones primitivas de ambas palabras.

Queda, para concluir, la reflexión sobre el alcance de esa dualidad de géneros inherente al sustantivo tizne que, como se ha explicado, asoma desde sus primeras manifestaciones en cas- 
tellano, se fortalece en textos de la literatura clásica y poco a poco va perdiendo fuerza a favor del masculino. En esta condición de sustantivo ambiguo, tizne se encuentra con sinónimos que también lo son (o lo han sido en su momento): pringue, mugre, arrastran vacilaciones semejantes hasta el día de hoy. Los tres han vivido alojados en el vocabulario tradicional del fuego y la lumbre y han encontrado su principal acomodo entre las cazuelas y las sartenes, con los sentidos de 'suciedad' y 'grasa'. Además, desde el punto de vista formal, todos terminan en - $e$ átona $y$, aunque pringue y mugre no son deverbales, su terminación en la vocal -e ha podido justificar las indeterminaciones de género apuntadas.

Por los cronistas de Indias y por otros autores posteriores se descubre que el femenino la tizne es forma frecuente en la historia del español, que convive con el masculino en las mismas sincronías y hasta alterna en algunos escritores, como hemos podido constatar en Benito Pérez Galdós, que en los Episodios nacionales emplea el femenino (puesto en boca de un guerrillero poco culto) y en Fortunata y Jacinta, el masculino, en un par de fragmentos narrativos en los que asoma su voz de narrador. No tenemos datos suficientes para afirmar, desde el punto de vista sociolingüístico, que el femenino pudiera estar estigmatizado en el siglo XIX para atribuir esa dualidad que refleja Galdós a razones de uso culto o popular. De los ejemplos encontrados hoy en las redes sociales, en la prensa periódica y en otros soportes ajenos a la literatura deducimos que el femenino mantiene cierta vitalidad en las provincias occidentales andaluzas y escasea en Hispanoamérica, porque el único ejemplo analizado, la cantina mexicana llamada "La Tizne Tacomotora", es poco representativo. Fuera de estos dominios, pervive como arcaísmo en nombres que designan fiestas populares, tan conservadores por la propia naturaleza de los conceptos que definen.

Por último, cabe reseñar la escasez del uso de tizne en plural. El CORDE proporciona siete ejemplos y, de ellos, solo uno muestra claramente el determinante masculino, un fragmento del relato breve titulado Pipá, de Clarín: “acudían muchos artesanos con los tiznes del trabajo en la cara”. El CREA ofrece cinco casos en plural, sin determinante, cuatro de ellos en obras de autores hispanoamericanos datadas en el último cuarto del siglo xx (Lisandro Otero, 
Jorge Enrique Adoun, Mario Vargas Llosa, José Donoso) y uno en el novelista español Javier Maqua. Algunos de ellos han trasladado el sentido original del sustantivo hacia el significado de 'manchado', 'impregnado' (de yeso, en Javier Maqua; de carmín labial en José Donoso; o de mala reputación, en el ejemplo de Lisandro Otero). Tal vez estos valores traslaticios ayudarán a tizne a mantener algo de vitalidad en la lengua española del siglo XXI.

De todos estos datos, por inducción, podrían distinguirse pautas generales para comprender determinadas tendencias de variación observadas siempre en el español, como ha sido la de las alternancias de género. Tal vez algún día, al analizar sus orígenes y sus peculiaridades en los textos a ambos lados del Atlántico, entendamos la génesis variacional de esta forma y de otras muchas de origen semejante. El estudio de sartén (Montero, 2019) y ahora la explicación del género ambiguo del sustantivo tizne abren una vía para seguir profundizando en los entresijos de la historia del género en español y, en concreto, en las alternancias entre el femenino y el masculino en estos y en otros sustantivos de similar linaje. Las bases de datos léxicas y los excelentes corpus de que disponemos allanarán, sin duda, el camino.

\section{Referencias}

Alarcos Llorach, E. (1994). Gramática de la lengua española. Madrid: Espasa-Calpe y Real Academia Española.

Alcina, J. y Blecua, J. M. (1983). Gramática española. Barcelona: Ariel.

Ambadiang, T. (1999). La flexión nominal: género y número. En I. Bosque y V. Demonte (dirs.), Gramática descriptiva de la lengua española, vol. 3 (pp. 4843-4914). Madrid: Espasa Calpe y Real Academia Española.

Corominas, J. y Pascual, J. A. (1986-1989). Diccionario crítico etimológico castellano e hispánico. 6 vols. Madrid: Gredos.

Díaz Hormigo, M. T. (2011). Sobre los denominados sustantivos deverbales de acción. Universidad Carlos in de Madrid. Grupo de Investigación "Lorenzo Hervás”. Recuperado de https://e-archivo.uc3m.es/ 
Mas Álvarez, I. (2004). Construcciones sintácticas de sustantivos deverbales: los complementos adnominales con de (tesis inédita de doctorado). Universidad de Santiago de Compostela, Santiago de Compostela, España.

Moliner, M. (1968). Diccionario de uso del español. Madrid: Gredos.

Montero Curiel, P. (2019). Reflexiones sobre el género del sustantivo sartén en la diacronía del español. Revista de Filología Española, 99(2), 333-355.

Pena, J. (1980). La derivación en español: Verbos derivados y sustantivos deverbales. Santiago de Compostela: Universidad de Santiago (anejo 16 de Verba).

PenA, J. (2012). Alteraciones de la serie derivativa verbo-nombre deverbal en español. Análisis genético. Zeitschrift für Romanische Philologie, 128(2), 319-349.

PenA, J. (2018). Alomorfia temática y sufijal en las formaciones deverbales sobre verbos irregulares de origen latino. En I. Bosque, S. Costa y M. Malcuori (eds.), Palabras en lluvia minuciosa. Veinte visitas a la gramática del español inspiradas por Ángela Di Tullio (pp. 253-271). Madrid-Fráncfort: Iberoamericana/Vervuert.

Quesada Pacheco, M. A. (2013). El español de América Central: Nivel morfosintáctico. Madrid-Fráncfort: Iberoamericana/Vervuert.

Real Academia Española y Asociación de Academias de la Lengua Española (2009). Nueva gramática de la lengua española. Madrid: Espasa Calpe.

Real Academia Española (2014). Diccionario de la lengua española. Vigésima tercera edición. Recuperado de http:// www.rae.es

Real Academia Española. Fichero general de la lengua española. Recuperado de <http.// http://web.frl.es/fichero.html>

Real Academia Española, Banco de datos (corde) [en línea]. Corpus diacrónico del español. Recuperado de http://www. rae.es

Real Academia Española, Banco de datos (corpes XXI) [en línea]. Corpus del español del siglo XXI (CORPES). Recuperado de http://www.rae.es 
Real Academia Española, Banco de datos (Crea) [en línea]. Corpus de referencia del español actual. Recuperado de http://www.rae.es

Real Academia Española, Nuevo tesoro lexicográfico de la lengua española. Recuperado de $<$ http://buscon.rae.es/ntlle/Srvlt GUILoginNtlle>

Rosenblat, Á. (1947). Género de los sustantivos en -e y en consonante. En Estudios dedicados a Menéndez Pidal II (pp. 161163). Madrid: Consejo Superior de Investigaciones Científicas.

Seco, M., Andrés, O. y Ramos, G. (1999). Diccionario del español actual. Madrid: Aguilar. 